
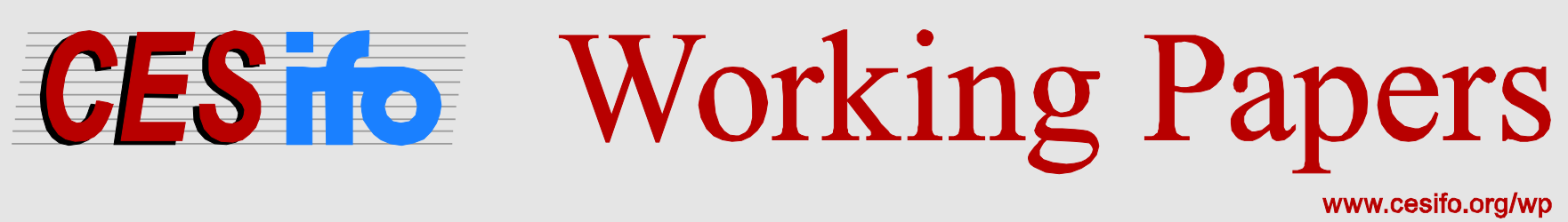

\title{
Market Power of the Input Supplier, Technology Transfer and Consumer Welfare
}

\author{
Jiyun Cao \\ Arijit Mukherjee
}

CESIFO WORKING PAPER NO. 5093

CATEGORY 11: INDUSTRIAL ORGANISATION

NOVEMBER 2014

An electronic version of the paper may be downloaded

- from the SSRN website:

- from the RePEc website:

- from the CESifo website:

WWW.SSRN.com

www.RePEc.org

www.CESifo-group.org/wp 


\title{
Market Power of the Input Supplier, Technology Transfer and Consumer Welfare
}

\begin{abstract}
It is believed that market power of the input supplier, charging a linear price, is detrimental for the consumers since it creates the double marginalisation problem. We show that this view may not be true if the final goods producers can adopt strategies to reduce rent extraction by the input supplier. Market power of the input supplier may encourage a final goods producer either to license its technology to a competitor or to adopt a less distortionary technology licensing contract. Both these effects may create higher consumer welfare under market power of the input supplier compared to a competitive input market.
\end{abstract}

JEL-Code: J510, L120, L130, L240.

Keywords: consumer surplus, labour union, technology licensing.

Jiyun Cao

The School of Economics

Nankai University

PR China - Tianjin, 300071

caojiyun@hotmail.com

\author{
Arijit Mukherjee* \\ Nottingham University \\ Business School \\ Jubilee Campus, Wollaton Road \\ UK - Nottingham, NG8 1BB \\ arijit.mukherjee@nottingham.ac.uk
}

*corresponding author

November 2014

Jiyun Cao acknowledges the Fundamental Research Fund for the Central University (Grant No. NKZXA1403) and the Humanities and Social Sciences Planning Fund from Chinese Ministry of Education (Grant No. 10YJA790008). The usual disclaimer applies. 


\title{
Market power of the input supplier, technology transfer and consumer
}

\author{
welfare
}

\section{Introduction}

It is usually believed that market power of the input supplier, charging a linear price, is detrimental for the consumers, since it creates the "double marginalisation" problem, thus creating a concern for the antitrust authorities. ${ }^{1}$ As mentioned in Inderst and Wey (2003), "Buyer power has also become an important issue in competition policy. In the United States, buyer power enters merger control as an efficiency defense via the 1992 Horizontal Merger Guidelines, with the revisions to Section 4 on efficiencies in 1997. The buyer-power defense has also been made explicit in the 1998 Competition Act of the United Kingdom. The buyerpower defense asserts that lower input prices due to higher purchasing power are passed (partially) on to consumers." Hirsch (1997) and Shrek (2009) show that the presence of a labour union, which is a natural candidate for charging a linear price, raises wages paid by the firms and makes the consumers worse off compared to the situation with no labour union.

We show in this paper that the above view may not be true if the final goods producers can adopt strategies to reduce rent extraction by the input supplier. More specifically, in this era of globalisation where firms are engaged in several profit raising activities such as international technology transfer, ${ }^{2}$ it would be more appropriate to consider the effects of market power of the input suppliers in conjunction with strategic technology transfer by the

\footnotetext{
${ }^{1}$ Linear pricing and two-part tariff are two important forms of contracts considered in the literature on vertical pricing. Our paper falls in the area of the extant literature considering linear vertical pricing. A seminal contribution with linear vertical pricing is by Ordover et al. (1990). For more recent contributions, one may look at Normann (2009) and the references therein. While the justification for two-part tariff contracts can be found in Tirole (1988), some plausible justifications for linear pricing can be found in Iyer and Villas-Boas (2003) and Milliou et al. (2005).

${ }^{2}$ See, e.g., Vishwasrao (2007) for evidences on international technology transfer.
} 
final goods producers. We show that market power of the input supplier may induce a final goods producer either to license its technology to a competitor or to charge a less distortionary technology licensing contract (more on this later), which, in turn, increases consumer surplus compared to the situation with a competitive input market.

In what follows, considering the input supplier as a labour union, we show in Section 2 that the presence of a labour union induces a monopolist final goods producer to license its technology to a foreign firm facing a competitive labour market, ${ }^{3}$ thus creating more productmarket competition. Product-market competition following technology transfer also reduces output of the licenser and therefore, the wage paid by the licenser. Both these effects tend to increase consumer surplus under labour union compared to the situation where the monopolist producer faces no labour union (or faces a competitive labour market), since the absence of a labour union may not induce technology licensing. ${ }^{4}$

We extend our analysis in Section 3 to consider a product-market competition to start with. In this situation, technology licensing occurs under both labour union and no labour union. However, the presence of a labour union may induce the licenser to charge a less distortionary technology licensing contract compared to the situation with no labour union, which, in turn, may make the consumers better off under labour union compared to no labour union. More specifically, the presence of a labour union may make the consumers better off

\footnotetext{
${ }^{3}$ The unilateral unionised labour market structure is also used in Bughin and Vannini (1995) and Mukherjee (2008). In reality, a large number of technologies are transferred from countries with labour unions to countries with no labour unions. For example, Chinese industries, which are effectively non-unionised industries (Metcalf and $\mathrm{Li}, 2005)$, receive a large number of technologies from other countries with labour unions. The appendix table 6-24 in Science and Engineering Indicators 2008 shows that U.S. receipt of royalties and license fees generated from exchange and use of manufacturing know-how with unaffiliated Chinese companies is 198 millions of U.S. Dollars in 2005. At the firm level, we can find that there is a significant amount of technology transfer between Nokia and China's Huawei (http://www.reuters.com/article/2008/09/29/nokia-huaweiidUSLR21747220080929).

${ }^{4}$ Even if the labour market is competitive, there can be reasons for licensing by a monopolist producer. For example, network externality (Economides, 1993), product differentiation (Wang and Yang, 1999, Mukherjee and Balasubramanian, 2001, Wang, 2002 and Faulí-Oller and Sandonis, 2002), strategic tariff policy (Mukherjee and Pennings, 2006) can induce technology licensing by a monopolist producer in an economy with a competitive labour market. We ignore all these aspects in our analysis.
} 
by changing the royalty only licensing contract under no labour union to either a fixed-fee only licensing contract or a two-part tariff licensing contract, with positive fixed-fee and output royalty, under a labour union. Hence, the presence of a labour union may reduce the marginal cost of the licensee, although it increases the marginal cost of the licenser. The presence of a labour union makes the consumers better off compared to no labour union if the market size is not large and the labour union's preference for wage over employment is moderate.

Thus, we show in a simple model that if a buyer has the opportunity to affect the productmarket competition for reducing the adverse effects of an input supplier's market power, a lower buyer power may make the consumers better off, which is in contrast to the usual belief that a higher buyer power increases consumer surplus by reducing the input price. ${ }^{5}$

It is worth noting that although we consider the input supplier as a labour union, which may put different weights on wage (i.e., the input price) and employment (i.e., the amount of input supplied), our results hold also for a profit maximizing input supplier giving the same weight on input price and the quantity sold. Further, to show our result in the simplest way, we assume that the foreign licensee faces a competitive input market, i.e., the foreign input supplier has no market power. Our results hold even if the foreign licensee faces an input supplier with a positive market power but the market power of the foreign input supplier is sufficiently lower than the market power of the domestic input supplier.

To the best of our knowledge, there is only another paper by Mukherjee and Wang (2013) showing the favourable effect of labour unions on consumers. However, our paper differs from theirs in some important ways. First, Mukherjee and Wang (2013) show that the presence of a labour union may make the consumers better off by attracting entry of an

\footnotetext{
${ }^{5}$ See Inderst and Wey (2003) for an alternative argument against higher buyer power. They suggest that higher bargaining power may not be desirable if it reduces the suppliers' investment incentives.
} 
independent firm that is significantly technologically superior compared to the incumbent firm. In contrast, there is no entry of firms in Section 3 of our analysis. Instead, the effects of a labour union on the technology licensing contract are responsible for our results. Second, there is a technology licensing induced entry in Section 2 of this paper. However, in our analysis, the licensee (which is the entrant) is technologically inferior compared to the licenser (which is the incumbent), whereas the entrant in Mukherjee and Wang (2013) needs to be significantly technologically superior compared to the incumbent. Hence, Mukherjee and Wang (2013) is more applicable in industries with leapfrogging of technologies where the new firms come with better technologies. In contrast, our paper is more applicable in industries with technology leaders.

Arya and Mittendorf (2006) and Mukherjee et al. (2008) showed that the presence of labour unions may induce a monopolist producer to license its technology to create productmarket competition. Unlike our paper, those papers neither examined the effects of labour unions on the technology licensing contracts among the established oligopolists nor looked at the effects of the labour unions on consumers in comparison to a competitive labour market.

Our paper can also be related to the literature on "second sourcing". Shepard (1987) and Farrell and Gallini (1988) showed that a monopolist input supplier may want to license its technology to create competition in the input market. The incentives for second sourcing in those papers are to ensure quality of input (Shepard, 1987) and to attract entry in the final goods market (Farrell and Gallini, 1988). Unlike those papers, licensing in our paper occurs in the final goods market and the purpose for licensing in our analysis is neither to ensure quality nor to create entry in another market (i.e., in the input market). Moreover, we consider the effects of a labour union on technology licensing among the established firms. 
Our paper certainly contributes to the literature on technology licensing also. Empirical evidence shows that technology transfer occurs under different types of licensing contracts. For example, Rostoker (1984) shows that licensing contracts differ significantly among the firms: up-front fixed-fee alone was used for $13 \%$, output royalty alone for $39 \%$ and the combination of fixed-fee and royalty for $46 \%$ of the time. More recently, Macho-Stadler et al. (1996) find, using Spanish data, that $59 \%$ of the contracts have output royalty alone, $13 \%$ include both royalty and fixed fee and $28 \%$ present a fixed fee alone. Our analysis shows that the presence of the labour union as well as the labour union's preference over wage and employment may be responsible for different types of licensing contracts. Hence, our reason for different licensing contracts is different from the existing reasons such as imitation (Rockett, 1990), asymmetric information or uncertainty (Gallini and Wright, 1990; Bousquet et. al., 1998), product differentiation (Mukherjee and Balasubramanian, 2001; Faulí-Oller and Sandonís, 2002), transportation cost of exporting (Mukherjee, 2007), the number of firms (Sen and Tauman, 2007) and asymmetric costs of production (Poddar and Sinha, 2010).

The remainder of the paper is organised as follows. Sections 2 and 3 consider respectively the situations of monopoly and duopoly market structures. Section 4 concludes.

\section{Monopoly final goods producer}

Consider two countries, called domestic and foreign, and the world market for a homogeneous good. There is a firm, firm 1, in the domestic country, which has a patented technology for the product. We assume that production requires only labour and firm 1 requires $\lambda(0<\lambda<1)$ workers to produce one unit of the output. We assume that the competitive wage in the domestic country is $c$.

We consider two labour market situations in the domestic country. 
1. Competitive labour market: In this situation, the domestic labour market is perfectly competitive and the equilibrium domestic wage is equal to the competitive wage, $c$.

2. Unionised labour market: In this situation, a labour union in the domestic country sets the wage, $w$, to maximise its utility $U=(w-c)^{\alpha} L^{1-\alpha}$, where $L$ is employment and $\alpha$, $0<\alpha<1$, (resp. $(1-\alpha))$ shows the labour union's preference for wage (resp. employment). We consider a right-to-manage model of labour union, where the union determines the wage and the firm hires workers according to its requirement. One may prefer to consider a wage bargaining between the firm and the union. Since technology licensing in our analysis creates a positive reservation payoff for firm 1 , it does not allow us to find an analytical solution for the wage bargaining. Hence, we consider that the labour union has full bargaining power and determines the wage. This assumption not only allows us to solve the model analytically, it also creates the maximum possible distortion created by the labour union. If $\alpha=\frac{1}{2}$, the objective function of the union will be like an objective function of a profit maximising input supplier. $^{6}$

We assume that firm 1 has the option to license its technology to a foreign firm, firm 2 , facing a competitive labour market. As mentioned above, we consider for simplicity that firm 2 faces a competitive labour market. Our result will hold even if firm 2 faces a unionised labour market but the union power faced by firm 2 is sufficiently lower than the union power faced by firm 1. We assume that the competitive wage in the foreign country is also $c$, where

\footnotetext{
${ }^{6}$ The equilibrium values will be similar if we consider a positive monotonic transformation of the union utility and assume that the union utility is $U=(w-c)^{2 \alpha} L^{2(1-\alpha)}$. If $\alpha=\frac{1}{2}$, the transformed union utility is $U=(w-c) L$, which is equal to the objective function of a profit maximising input supplier.
} 
$c<\frac{a}{\lambda} .{ }^{7}$ Firm 2 is not able to produce the good without firm 1's technology. However, if firm 2 gets the technology of firm 1, it competes with firm 1 like a Cournot duopolist.

Few remarks are in order at this point. First, we consider the same competitive wages in both countries. Thus, we eliminate the incentive for technology licensing created by a lower competitive wage in the foreign country. Similarly, we eliminate the possibility of creating a higher consumer surplus due to a lower competitive wage in the foreign country. Hence, our result is not influenced by the differences in the competitive wages.

Second, like many other works on international technology licensing (see, e.g., Mottiner and Johnson, 2000, Kabiraj and Marjit, 2003, Mukherjee and Pennings, 2006 and Feess et al. 2009) we assume away foreign direct investment (FDI) by firm 1 due to an actual or perceived (e.g., due to political instability) high cost or risks associated with FDI. ${ }^{8}$ In other words, like other papers on international technology licensing, it is implicit in our analysis that licensing dominates other strategies such as FDI. It may worth pointing out that if the cost of FDI is not high, firm 1 would prefer to undertake FDI in the foreign country to bypass the unionised wage in the domestic country. ${ }^{9}$ However, the same competitive wages in both countries, as assumed in this paper, implies that FDI by firm 1 does not increase consumer surplus in the presence of a domestic labour union compared to the situation with no domestic labour union.

Third, following the literature on technology licensing (see, e.g., Katz and Shapiro, 1985, Rockett, 1990, Kabiraj and Marjit, 2003, Mukherjee and Pennings, 2006, Sen and Tauman,

\footnotetext{
${ }^{7}$ This condition is to guarantee that the production always occurs no matter whether firm 1 transfers its technology or not.

${ }^{8}$ Many studies (see, e.g., Buckley and Casson,1981; Smith, 1987; Horstmann and Markusen, 1987; Horstmann and Markusen, 1992; Motta, 1992) have recognised that FDI is costly because it requires the firm to build a new production facility.

${ }^{9}$ See Mukherjee and Suetrong (2012) for a recent paper showing the effects of domestic labour unions on outward FDI.
} 
2007 and Yang and Maskus, 2009), we assume that firms 1 and 2 compete in the productmarket ex-post technology licensing. Hence, we assume that firm 1 cannot commit credibly (maybe due to the problem of enforcing) that it will not sell in this market ex-post licensing. For example, firm 1 can invent around its initial technology and enter the market with similar technology. Alternatively, firm 1 can register itself as a new firm and can enter the market as a different firm. If feasible, firm 1 prefers exclusive production by firm 2 ex-post licensing, since it does not increase competition in the product market and helps to bypass the domestic labour union. However, following the discussion in the last paragraph, it is immediate that the exclusive production by firm 2 does not increase consumer surplus in the presence of a domestic labour union compared to a competitive domestic labour market.

We consider the following game. At stage 1, firm 1 decides whether or not to license its technology to firm 2. In case of licensing, firm 1 offers a take-it-or-leave-it two-part tariff licensing contract with an up-front non-negative fixed-fee $(F)$ and a non-negative per-unit output royalty $(r) .{ }^{10}$ Firm 2 accepts the licensing contract if it is not worse off under licensing compared to no licensing. At stage 2, the wages are determined. The equilibrium wage in the domestic country is $c$ under no labour union. If there is a domestic labour union, it determines wage, $w$, to maximise its utility. The equilibrium wage in the foreign country is $c$. At stage 3 , the firms determine their outputs simultaneously if licensing occurs. Otherwise, firm 1 produces like a monopolist. The profits are realised. We solve the game through backward induction.

\footnotetext{
${ }^{10}$ The non-negativity constraints on the fixed-fee and output royalty follow the tradition of the technology licensing literature and may be motivated by the antitrust requirement (see, e.g., Rockett, 1990, Faulí-Oller and Sandonis, 2002 and Mukherjee and Pennings, 2006).
} 
To show our results in the simplest way, we assume that there are no trade costs or costs related to technology licensing. We assume that the inverse market demand function for the product is $P=a-q$, where $P$ is price and $q$ is the total output.

\subsection{No labour union in the domestic country}

If there is no labour union in the domestic country, the equilibrium wages are $c$ in both countries. In this situation, the monopolist, firm 1, has no incentive to license its technology. Firm 1 determines its output to maximise its profit $\pi_{1}=\left(a-q_{1}-\lambda c\right) q_{1}$. Straightforward calculation gives the equilibrium output and consumer surplus as $q_{1}^{m n}=\frac{a-\lambda c}{2}$ and $C S^{m n}=\frac{(a-\lambda c)^{2}}{8}$ respectively.

\subsection{A labour union in the domestic country}

Now assume that there is a labour union in the domestic country.

\subsubsection{No licensing}

If technology licensing does not occur, given the domestic unionised wage, $w$, firm 1 determines its output to maximise its profit $\pi_{1}=\left(a-q_{1}-\lambda w\right) q_{1}$. Straightforward calculation gives the profit-maximising output of firm 1 as $q_{1}^{m u n}=\frac{a-\lambda w}{2}$. 
The labour demand in the domestic country is $L=\lambda q_{1}^{m u n}=\frac{\lambda(a-\lambda w)}{2}$. The labour union maximises its utility $U=(w-c)^{\alpha} L^{1-\alpha}=(w-c)^{\alpha}\left[\frac{\lambda(a-\lambda w)}{2}\right]^{1-\alpha}$ to determine the wage. The equilibrium wage is $w^{m u n}=\frac{\alpha a}{\lambda}+(1-\alpha) c$ which increases with $\alpha$.

Thus, the equilibrium output and profit of firm 1 are $q_{1}^{m u n}=\frac{(1-\alpha)(a-\lambda c)}{2}$ and $\pi_{1}^{m u n}=\frac{(1-\alpha)^{2}(a-\lambda c)^{2}}{4}$ respectively.

\subsubsection{Licensing}

If technology licensing occurs, given the domestic unionised wage, $w$, the profits of two firms in stage 3 are respectively $\pi_{1}=(a-q-\lambda w) q_{1}+r q_{2}+F$ and $\pi_{2}=(a-q-\lambda c-r) q_{2}-F$, where $q=q_{1}+q_{2}, F$ is the up-front licensing fee and $r$ is the per-unit output royalty.

We get the equilibrium outputs of the firms as $q_{1}^{m u l}=\frac{a-2 \lambda w+\lambda c+r}{3}$ and $q_{2}^{m u l}=\frac{a+\lambda w-2 \lambda c-2 r}{3}$. Hence, in stage 2 , the labour demand in the domestic country is $L=\lambda q_{1}^{m u l}=\frac{\lambda(a-2 \lambda w+\lambda c+r)}{3}$ and the labour union maximises its utility $U=(w-c)^{\alpha} L^{1-\alpha}=(w-c)^{\alpha}\left[\frac{\lambda(a-2 \lambda w+\lambda c+r)}{3}\right]^{1-\alpha}$ to determine the wage. The equilibrium wage is $w^{m u l}=\frac{\alpha(a+\lambda c+r)}{2 \lambda}+(1-\alpha) c$ which increases with $\alpha$ and $r$. 
Accordingly, the profit-maximising outputs and profits of the firms under licensing are

$$
\begin{aligned}
& q_{1}^{m u l}=\frac{(1-\alpha)(a-\lambda c+r)}{3} \quad, \quad q_{2}^{m u l}=\frac{(2+\alpha)(a-\lambda c)-(4-\alpha) r}{6} \\
& \pi_{1}^{m u l}=\frac{(1-\alpha)^{2}(a-\lambda c+r)^{2}}{9}+\frac{[(2+\alpha)(a-\lambda c)-(4-\alpha) r] r}{6}+F \\
& \pi_{2}^{m u l}=\frac{[(2+\alpha)(a-\lambda c)-(4-\alpha) r]^{2}}{36}-F .
\end{aligned}
$$

At stage 1, firm 1 maximises the following expression to determine the equilibrium licensing contract:

$$
\underset{r, F}{\operatorname{Max}} \pi_{1}^{m u l}
$$

subject to $\pi_{1}^{m u l} \geq \pi_{1}^{m u n}$

$$
\begin{aligned}
& \pi_{2}^{m u l} \geq 0 \\
& r, F \geq 0 \text { and } q_{1}^{m u l}, q_{2}^{m u l}>0,
\end{aligned}
$$

where (2) and (3) are the participation constraints of firms 1 and 2 respectively.

Since firm 1 offers a take-it-or-leave-it licensing contract to firm 2 , the equilibrium $F$ is such that firm 2 earns the same net profits under licensing and no licensing. Hence, the equilibrium fixed-fee is $F=\frac{[(2+\alpha)(a-\lambda c)-(4-\alpha) r]^{2}}{36}$.

Thus, (1) reduces to

$$
\operatorname{Max}_{r} \pi_{1}^{m u l}=\frac{(1-\alpha)^{2}(a-\lambda c+r)^{2}}{9}+\frac{[(2+\alpha)(a-\lambda c)-(4-\alpha) r] r}{6}+\frac{[(2+\alpha)(a-\lambda c)-(4-\alpha) r]^{2}}{36} .
$$

We have the first order derivative of $\pi_{1}^{m u l}$ with respect to $r$ as follows.

$$
\frac{\partial \pi_{1}^{m u l}}{\partial r}=\frac{(2-5 \alpha)(1-\alpha)(a-\lambda c)-\left(4+10 \alpha-5 \alpha^{2}\right) r}{18} .
$$


It can be found from (4) that the equilibrium non-negative per-unit royalty and fixed-fee in the technology licensing contract are $r^{m u l}=0$ and $F^{m u l}=\frac{[(2+\alpha)(a-\lambda c)]^{2}}{36}$ for $\frac{2}{5} \leq \alpha<1$, and $r^{m u l}=\frac{(2-5 \alpha)(1-\alpha)(a-\lambda c)}{4+10 \alpha-5 \alpha^{2}}$ and $F^{m u l}=\left[\frac{9 \alpha(2-\alpha)(a-\lambda c)}{2\left(4+10 \alpha-5 \alpha^{2}\right)}\right]^{2}$ for $0<\alpha<\frac{2}{5}$. It can be demonstrated that the equilibrium royalty rate decreases as the preference of the labour union for wage over employment increases for $0<\alpha<\frac{2}{5}$. A higher weight on wage over employment induces the labour union to charge a relatively higher wage in equilibrium, which, in turn, induces firm 1 to shift more production to firm 2 by charging a less distortionary licensing contract, implying a lower royalty rate.

Accordingly, the equilibrium outputs and profits of the firms, and consumer surplus are $q_{1}^{m u l}=\frac{(1-\alpha)(a-\lambda c)}{3}, q_{2}^{m u l}=\frac{(2+\alpha)(a-\lambda c)}{6}, \pi_{1}^{m u l}=\frac{\left(8-4 \alpha+5 \alpha^{2}\right)(a-\lambda c)^{2}}{36}, \pi_{2}^{m u l}=0$ and $C S^{m u l}=\frac{[(4-\alpha)(a-\lambda c)]^{2}}{72}$ for $\frac{2}{5} \leq \alpha<1$, but they are $q_{1}^{m u l}=\frac{(2+\alpha)(1-\alpha)(a-\lambda c)}{4+10 \alpha-5 \alpha^{2}}$ $q_{2}^{m u l}=\frac{9 \alpha(2-\alpha)(a-\lambda c)}{2\left(4+10 \alpha-5 \alpha^{2}\right)} \quad, \quad \pi_{1}^{m u l}=\frac{[(2+\alpha)(a-\lambda c)]^{2}}{4\left(4+10 \alpha-5 \alpha^{2}\right)} \quad, \quad \pi_{2}^{m u l}=0 \quad$ and $C S^{m u l}=\frac{\left[\left(4+16 \alpha-11 \alpha^{2}\right)(a-\lambda c)\right]^{2}}{8\left(4+10 \alpha-5 \alpha^{2}\right)^{2}}$ for $0<\alpha<\frac{2}{5}$.

We get that the profit of firm 1 and consumer surplus are higher under licensing compared to no licensing, i.e., $\pi_{1}^{m u l}>\pi_{1}^{m u n}$ and $C S^{m u l}>C S^{m n}$ for $0<\alpha<1$, thus giving us the following proposition immediately. 
Proposition 1: Compared to the situation with no labour union (or a competitive labour market), the presence of a domestic labour union (i) induces the monopolist producer to license its technology to a foreign non-unionised firm, with a fixed-fee licensing contract for $\frac{2}{5} \leq \alpha \leq 1$ and with a two-part tariff licensing contract involving a positive fixed-fee and a positive output royalty for $0<\alpha<\frac{2}{5}$, and (ii) makes the consumers better off.

The presence of a labour union (compared to no labour union) in the domestic country increases the marginal cost of firm 1, which induces firm 1 to shift its production to the foreign country. The shift of production to the foreign country from the domestic country has opposite effects on firm 1's profit. On one hand, it creates a negative effect on firm 1's profit by creating product-market competition, on the other hand, it creates positive effects on firm 1's profit by reducing the domestic unionised wage as well as by bypassing the unionised wage for the amount produced by firm 2 . Firm 1 creates a balance between these opposite effects by designing a suitable licensing contract with fixed-fee and output royalty. As the labour union's preference for wage over employment increases, it creates a higher wage in the domestic country before licensing, thus increasing firm 1's incentive to shift its production to firm 2. Hence, firm 1's incentive for distorting the output of firm 2 through royalty decreases as the domestic labour union's preference for wage over employment increases. As a result, the equilibrium licensing contract involves a fixed-fee and royalty for $0<\alpha<\frac{2}{5}$, but only a fixed-fee for $\frac{2}{5} \leq \alpha \leq 1$. 
Irrespective of the equilibrium licensing contract, the technology transfer resulted from the presence of a labour union increases product-market competition and decreases firm 1's marginal cost of production, leading to a higher total output and consumer surplus.

Since Proposition 1 holds for $\alpha=\frac{1}{2}$, it is immediate that our result will hold even if the input supplier is not a labour union but a profit maximising input supplier.

\section{Duopoly market structure}

We have shown in the previous section that the presence of a labour union induces a monopolist producer to license its technology to a foreign firm, while licensing does not occur in the absence of a labour union. Hence, licensing increases the number of producers in the previous section. We will show in this section that even if the number of firms remains the same under labour union and no labour union, and licensing occurs under both no labour union and labour union in the domestic country, the presence of a labour union may increase consumer surplus by creating a less distortionary licensing contract.

We assume in this section that both firms 1 and 2 considered in the previous section have technologies to produce the product. However, firm 1 has a better production technology than firm 2. As before, we assume that firm 1 needs $\lambda(0<\lambda<1)$ workers to produce one unit of the output. However, firm 2 requires 1 worker to produce one unit of the output. Hence, labour productivity is lower in firm 2 compared to firm 1.

We consider the following game. At stage 1, firm 1 decides whether or not to license its technology to firm 2. In case of licensing, firm 1 offers a take-it-or-leave-it two-part tariff licensing contract with an up-front non-negative fixed-fee and a non-negative per-unit output royalty. Firm 2 accepts the licensing contract if it is not worse off under licensing compared to no licensing. At stage 2, the wages are determined. The equilibrium wage in the domestic 
country is $c$ under no labour union. If there is a domestic labour union, it determines wage, $w$, to maximise its utility. The equilibrium wage in the foreign country is $c$. At stage 3, the firms determine their outputs simultaneously and the profits are realised. We solve the game through backward induction.

We assume in this section that $c<\frac{a}{2-\lambda}$ so that two firms always produce positive outputs.

\subsection{No labour union in the domestic country}

First consider the case where labour markets in both countries are perfectly competitive. Hence, the equilibrium wages are $c$ in both countries.

\subsubsection{No licensing}

Firms 1 and 2 determine their outputs simultaneously to maximise $\pi_{1}=(a-q-\lambda c) q_{1}$ and $\pi_{2}=(a-q-c) q_{2}$ respectively, where $q=q_{1}+q_{2}$. Straightforward calculation gives the equilibrium outputs and profits of the firms as $q_{1}^{d n n}=\frac{a-2 \lambda c+c}{3}, q_{2}^{d n n}=\frac{a+\lambda c-2 c}{3}$, $\pi_{1}^{d n n}=\frac{(a-2 \lambda c+c)^{2}}{9}$ and $\pi_{2}^{d n n}=\frac{(a+\lambda c-2 c)^{2}}{9}$.

\subsubsection{Licensing}

If technology licensing occurs, the profits of the firms in the stage 3 are respectively $\pi_{1}=(a-q-\lambda c) q_{1}+r q_{2}+F$ and $\pi_{2}=(a-q-\lambda c-r) q_{2}-F$. 
We get that the equilibrium outputs and profits under licensing as $q_{1}^{d n l}=\frac{a-\lambda c+r}{3}$, $q_{2}^{d n l}=\frac{a-\lambda c-2 r}{3}, \pi_{1}^{d n l}=\frac{(a-\lambda c+r)^{2}}{9}+\frac{(a-\lambda c-2 r) r}{3}+F$ and $\pi_{2}^{d n l}=\frac{(a-\lambda c-2 r)^{2}}{9}-F$.

Firm 1 maximises the following expression to determine the equilibrium licensing contract:

$$
\underset{r, F}{\operatorname{Max}} \pi_{1}^{d n l}
$$

subject to $\pi_{1}^{d n l} \geq \pi_{1}^{d n n}$

$$
\begin{aligned}
& \pi_{2}^{d n l} \geq \pi_{2}^{d n n} \\
& r, F \geq 0 \text { and } q_{1}^{d n l}, q_{2}^{d n l}>0,
\end{aligned}
$$

where (6) and (7) are the participation constraints of firms 1 and 2 respectively. It is obvious from (7) that firm 2 will not accept the licensing contract if $r>(1-\lambda) c$. Hence, the equilibrium royalty rate must satisfy $0 \leq r \leq(1-\lambda) c$.

Since firm 1 offers a take-it-or-leave-it licensing contract to firm 2 , the equilibrium fixedfee makes firm 2 indifferent under licensing and no licensing, giving us the equilibrium fixed-fee as $F=\frac{(a-\lambda c-2 r)^{2}}{9}-\frac{(a+\lambda c-2 c)^{2}}{9}$.

Hence, (5) reduces to

$$
\operatorname{Max}_{r} \pi_{1}^{d n l}=\frac{(a-\lambda c+r)^{2}}{9}+\frac{(a-\lambda c-2 r) r}{3}+\frac{(a-\lambda c-2 r)^{2}}{9}-\frac{(a+\lambda c-2 c)^{2}}{9} .
$$

The first order derivative of $\pi_{1}^{d n l}$ with respect to $r$ is:

$$
\frac{\partial \pi_{1}^{d n l}}{\partial r}=\frac{a-\lambda c-2 r}{9} .
$$


It is immediate from (8) that the equilibrium non-negative per-unit royalty and fixed-fee are $r^{d n l}=(1-\lambda) c$ and $F^{d n l}=0$ respectively. Accordingly, the equilibrium outputs and profits of firms 1 and 2, and consumer surplus are $q_{1}^{d n l}=\frac{a-2 \lambda c+c}{3}, \quad q_{2}^{d n l}=\frac{a+\lambda c-2 c}{3}$, $\pi_{1}^{d n l}=\frac{(a-2 \lambda c+c)^{2}}{9}+\frac{(a+\lambda c-2 c)(1-\lambda) c}{3} \quad, \quad \pi_{2}^{d n l}=\frac{(a+\lambda c-2 c)^{2}}{9} \quad$ and $C S^{d n l}=\frac{(2 a-\lambda c-c)^{2}}{18}$

The above results indicate that in the absence of labour union, firm 1 always licenses its technology to firm 2 and charges an output royalty only. As a result, the consumer surplus is the same under licensing and no licensing. This is similar to the existing literature on technology licensing with perfectly competitive input markets such as Rockett (1990) and Sen and Tauman (2007).

\subsection{A labour union in the domestic country}

Now we want to see the effects of a domestic labour union on the technology licensing contract.

\subsubsection{No licensing}

First, consider the case of no licensing under labour union.

In stage 3 , the marginal costs of firms 1 and 2 are $\lambda w$ and $c$ respectively. Hence, firms 1 and 2 determine their outputs simultaneously to maximise $\pi_{1}=(a-q-\lambda w) q_{1}$ and $\pi_{2}=(a-q-c) q_{2}$ respectively 
We get the equilibrium outputs as $q_{1}^{d u n}=\frac{a-2 \lambda w+c}{3}$ and $q_{2}^{d u n}=\frac{a+\lambda w-2 c}{3}$. Hence, in stage 2 , the labour demand in the domestic country is $L=\lambda q_{1}^{d u n}=\frac{\lambda(a-2 \lambda w+c)}{3}$. The domestic labour union maximises its utility $U=(w-c)^{\alpha} L^{1-\alpha}=(w-c)^{\alpha}\left[\frac{\lambda(a-2 \lambda w+c)}{3}\right]^{1-\alpha}$ to determine the wage. The equilibrium wage is $w^{d u n}=\frac{\alpha(a+c)}{2 \lambda}+(1-\alpha) c$ which increases with $\alpha$.

Accordingly, the equilibrium outputs and profits under no licensing are respectively

$$
\begin{aligned}
& q_{1}^{d u n}=\frac{(1-\alpha)[a-\lambda c+(1-\lambda) c]}{3} \quad, \quad q_{2}^{d u n}=\frac{(2+\alpha)(a-\lambda c)-(4-\alpha)(1-\lambda) c}{6} \\
& \pi_{1}^{d u n}=\frac{(1-\alpha)^{2}[a-\lambda c+(1-\lambda) c]^{2}}{9} \text { and } \pi_{2}^{d u n}=\frac{[(2+\alpha)(a-\lambda c)-(4-\alpha)(1-\lambda) c]^{2}}{36} .
\end{aligned}
$$

\subsubsection{Licensing}

Now consider licensing by firm 1 . The stages 2 and 3 are similar to that in section 2.2.2, and we get the equilibrium wage, outputs and profits under licensing respectively as $w^{d u l}=\frac{\alpha(a+\lambda c+r)}{2 \lambda}+(1-\alpha) c, q_{1}^{d u l}=\frac{(1-\alpha)(a-\lambda c+r)}{3}, q_{2}^{d u l}=\frac{(2+\alpha)(a-\lambda c)-(4-\alpha) r}{6}$, $\pi_{1}^{d u l}=\frac{(1-\alpha)^{2}(a-\lambda c+r)^{2}}{9}+\frac{[(2+\alpha)(a-\lambda c)-(4-\alpha) r] r}{6}+F$ and $\pi_{2}^{d u l}=\frac{[(2+\alpha)(a-\lambda c)-(4-\alpha) r]^{2}}{36}-F$

In stage 1 , firm 1 maximises the following expression to determine the equilibrium licensing contract: 


$$
\underset{r, F}{\operatorname{Max}} \pi_{1}^{d u l}
$$

subject to $\pi_{1}^{d u l} \geq \pi_{1}^{d u n}$

$$
\begin{aligned}
& \pi_{2}^{d u l} \geq \pi_{2}^{d u n} \\
& r, F \geq 0 \text { and } q_{1}^{d u l}, q_{2}^{d u l}>0,
\end{aligned}
$$

where (10) and (11) are the participation constraints of firms 1 and 2 respectively. It is obvious from (11) that firm 2 will not accept the licensing contract if $r>(1-\lambda) c$. Hence, the equilibrium royalty rate must satisfy $0 \leq r \leq(1-\lambda) c$.

Since firm 1 offers a take-it-or-leave-it licensing contract to firm 2 , the equilibrium fixedfee that makes firm 2 indifferent between licensing and no licensing is $F=\frac{[(2+\alpha)(a-\lambda c)-(4-\alpha) r]^{2}}{36}-\frac{[(2+\alpha)(a-\lambda c)-(4-\alpha)(1-\lambda) c]^{2}}{36}$

Hence, (9) reduces to

$$
\begin{aligned}
\operatorname{Max}_{r} \pi_{1}^{d u l} & =\frac{(1-\alpha)^{2}(a-\lambda c+r)^{2}}{9}+\frac{[(2+\alpha)(a-\lambda c)-(4-\alpha) r] r}{6} \\
& +\frac{[(2+\alpha)(a-\lambda c)-(4-\alpha) r]^{2}}{36}-\frac{[(2+\alpha)(a-\lambda c)-(4-\alpha)(1-\lambda) c]^{2}}{36} .
\end{aligned}
$$

We have the first order derivative of $\pi_{1}^{d u l}$ with respect to $r$ as follows:

$$
\frac{\partial \pi_{1}^{d u l}}{\partial r}=\frac{(2-5 \alpha)(1-\alpha)(a-\lambda c)-\left(4+10 \alpha-5 \alpha^{2}\right) r}{18}
$$

We get that $\frac{\partial \pi_{1}^{d u l}}{\partial r} \leq 0$ for $\frac{2}{5} \leq \alpha<1$, implying that the equilibrium royalty is $r^{d u l}=0$ for $\frac{2}{5} \leq \alpha<1$. Hence, a fixed-fee licensing occurs for $\frac{2}{5} \leq \alpha<1$ and the equilibrium fixed-fee is $F^{d u l}=\frac{(4-\alpha)(1-\lambda) c[2(2+\alpha)(a-\lambda c)-(4-\alpha)(1-\lambda) c]}{36}$. It is easy to demonstrate that the 
profit $\pi_{1}^{d u l}=\frac{(1-\alpha)^{2}(a-\lambda c)^{2}}{9}+\frac{(4-\alpha)(1-\lambda) c[2(2+\alpha)(a-\lambda c)-(4-\alpha)(1-\lambda) c]}{36}, \quad$ is greater than that of under no licensing. Hence, licensing is profitable in this situation.

If $0<\alpha<\frac{2}{5}$, the equilibrium output royalty is $r^{d u l}=(1-\lambda) c$ for

$$
\frac{(2-5 \alpha)(1-\alpha)(a-\lambda c)}{4+10 \alpha-5 \alpha^{2}} \geq(1-\lambda) c
$$

but it is $r^{d u l}=\frac{(2-5 \alpha)(1-\alpha)(a-\lambda c)}{4+10 \alpha-5 \alpha^{2}}$ if (12) does not hold. We get that (12) holds for $0<\alpha \leq \bar{\alpha}$ where $\bar{\alpha}=\frac{7 a+10 c-17 \lambda c-3 \sqrt{a^{2}+20 c^{2}+41 \lambda^{2} c^{2}-60 \lambda c^{2}+20 a c-22 \lambda a c}}{10(a+c-2 \lambda c)} \in\left(0, \frac{2}{5}\right) .{ }^{11}$

Hence, if $0<\alpha \leq \bar{\alpha}$, the equilibrium royalty is $r^{d u l}=(1-\lambda) c$, the equilibrium fixed-fee is $F^{d u l}=0$ and the equilibrium profit of firm 1 is $\pi_{1}^{d u l}=\frac{(1-\alpha)^{2}[a-\lambda c+(1-\lambda) c]^{2}}{9}+\frac{[(2+\alpha)(a-\lambda c)-(4-\alpha)(1-\lambda) c](1-\lambda) c}{6}$, which is greater than firm 1's profit under no licensing.

If $\bar{\alpha}<\alpha<\frac{2}{5}$, the equilibrium output royalty is $r^{d u l}=\frac{(2-5 \alpha)(1-\alpha)(a-\lambda c)}{4+10 \alpha-5 \alpha^{2}}$, and the corresponding $F^{d u l}=\frac{\left[(2+\alpha)(a-\lambda c)-(4-\alpha) r^{d u l}\right]^{2}}{36}-\frac{[(2+\alpha)(a-\lambda c)-(4-\alpha)(1-\lambda) c]^{2}}{36}>0$. Hence,

${ }^{11}$ It is easy to check that (12) holds for $\alpha=0$ but it does not hold for $\alpha=\frac{2}{5}$. Since (12) is continuous in $\alpha \in\left[0, \frac{2}{5}\right]$, it is immediate that there exists a $\alpha=\bar{\alpha}$ such that (12) holds for $0<\alpha \leq \bar{\alpha}$. 
the equilibrium licensing contract is a combination of a positive fixed-fee and a positive royalty for $\bar{\alpha}<\alpha<\frac{2}{5}$. It is easy to understand that the corresponding equilibrium profit of firm 1 is greater than its profit under no licensing. This happens for the following reason. If $\bar{\alpha}<\alpha<\frac{2}{5}$, firm 1 could charge a royalty rate $r^{d u l}=(1-\lambda) c$ and could get a higher profit compared to its profit under no licensing. Since firm 1 charges a royalty rate $r^{d u l}=\frac{(2-5 \alpha)(1-\alpha)(a-\lambda c)}{4+10 \alpha-5 \alpha^{2}}$ instead of the royalty rate $r^{d u l}=(1-\lambda) c$, it must be that firm 1 earns higher profit under the former royalty rate (along with the corresponding positive fixed-fee) than the latter royalty rate (and no fixed-fee), which immediately implies that firm 1's profit under the former royalty rate is higher than its profit under no licensing.

The above discussion gives the following proposition immediately.

Proposition 2: In contrast to the royalty only licensing under no labour union (or a competitive labour market), the equilibrium licensing contracts in the presence of a domestic labour union are as follows: (a) Royalty only licensing contract for $0<\alpha \leq \bar{\alpha}$, (b) A two-part tariff licensing contract with a positive fixed-fee and a positive royalty for $\bar{\alpha}<\alpha<\frac{2}{5}$, and (c) A licensing contract with fixed-fee only for $\frac{2}{5} \leq \alpha<1$.

The above result is in contrast to existing literature (see, e.g., Rockett, 1990 and Sen and Tauman, 2007) showing that the licenser offers a royalty only licensing contract in the case of a homogeneous duopoly with no imitation. 
The reason for Proposition 2 is as follows. Firm 1's marginal cost of production under licensing is $\lambda w^{d u l}=\frac{\alpha(a+\lambda c+r)}{2}+(1-\alpha) \lambda c$, implying that technology licensing reduces firm 1's marginal cost of production by $\frac{\alpha[(1-\lambda) c-r]}{2}$ by reducing the wage charged by the domestic labour union. Hence, the royalty rate creates two opposing effects on firm 1's profits under licensing. On one hand, a lower royalty creates a negative effect on firm 1's market share by making firm 2 more competitive in the product market. On the other hand, a lower royalty creates a positive effect on firm 1's profit by reducing the domestic unionised wage, and this benefit increases with a higher $\alpha$. If $\alpha$ is high enough $\left(\frac{2}{5} \leq \alpha<1\right)$, the benefit from domestic wage reduction outweighs firm 1's loss of market share for a lower royalty rate, inducing firm 1 to charge a fixed-fee only licensing contract. On the other hand, if $\alpha$ is low enough $(0<\alpha \leq \bar{\alpha})$, firm 1's loss of market share dominates its benefit from lower domestic wage and induces firm 1 to charge a royalty only licensing contract. If $\alpha$ is moderate $\left(\bar{\alpha}<\alpha<\frac{2}{5}\right)$, firm 1 charges both positive fixed-fee and positive royalty to balance these effects.

Given the equilibrium licensing contracts shown above, we are now in a position to show the effects of labour union on consumer surplus compared to no labour union. Since both firms always produce positive outputs, we can find that consumer surplus is positively related to the total output, which is negatively related to the total marginal costs of the firms (Varian, 1992). Hence, it is enough for us to compare the total marginal costs of the firms under "no labour union and licensing" and "labour union and licensing". 
Since the royalty rate under no labour union is $r^{d n l}=(1-\lambda) c$, the total marginal costs of the firms under no labour union is $T M C^{n l u, l}=\lambda c+c$.

The total marginal costs of the firms in the presence of labour union are $T M C^{l u, l}=\lambda w^{d u l}+c \quad$ for $\quad 0<\alpha \leq \bar{\alpha}, \quad T M C^{l u, l}=\lambda w^{d u l}+\lambda c+r^{d u l}$ for $\quad \bar{\alpha}<\alpha<\frac{2}{5}$, where $r^{d u l} \in(0,(1-\lambda) c)$ and $T M C^{l u, l}=\lambda w^{d u l}+\lambda c$ for $\frac{2}{5} \leq \alpha<1$

Since $c<w^{d u l}$, it is immediate that if firm 1 offers a royalty only contract under both no labour union and labour union, which occurs for $0<\alpha \leq \bar{\alpha}$, the consumer surplus is higher under no labour union than under labour union.

Next, consider the other extreme case where firm 1 offers a royalty only contract under no labour union but it offers a fixed-fee only contract under labour union, which occurs for $\frac{2}{5} \leq \alpha<1$. We get that $T M C^{l u, l}<(>) T M C^{n l u, l}$ or $\lambda w^{d u l}<(>) c$ if $\alpha<(>) \frac{2(1-\lambda) c}{a-\lambda c} \equiv \alpha^{*}$. We find that $\alpha^{*}<1$ and $\frac{2}{5}<\alpha^{*}$ if $a<(5-4 \lambda) c$. Since the requirement for positive outputs implies that $(2-\lambda) c<a$, the above discussion implies that if $\frac{2}{5} \leq \alpha<1$, consumer surplus is higher under labour union compared to no labour union if $(2-\lambda) c<a<(5-4 \lambda) c$ (ensuring $\left.\frac{2}{5}<\alpha^{*}<1\right)$ and $\frac{2}{5}<\alpha<\alpha^{*}$

Finally, consider the case where firm 1 offers a royalty only licensing under no labour union but it offers a two-part tariff licensing contract with a positive fixed-fee and a positive royalty in the presence of a domestic labour union. This happens for $\bar{\alpha}<\alpha<\frac{2}{5}$. We get that $T M C^{l u, l}>T M C^{n l u, l}$ or $\lambda w^{d u l}+r^{d u l}>c$ at $\alpha=\bar{\alpha}$ but $T M C^{l u, l}<T M C^{n l u, l}$ or $\lambda w^{d u l}+r^{d u l}<c$ at 
$\alpha=\frac{2}{5}$ if $a<(5-4 \lambda) c$. Since the difference $\left(\lambda w^{d u l}+r^{d u l}-c\right)$ is continuous and decreasing with respect to $\alpha$ over $\alpha \in\left[\bar{\alpha}, \frac{2}{5}\right],{ }^{12}$ we get that if $a<(5-4 \lambda) c$, there exists a $\alpha=\hat{\alpha} \in\left(\bar{\alpha}, \frac{2}{5}\right)$ such that consumer surplus is higher under labour union compared to no labour union for $\alpha \in\left(\hat{\alpha}, \frac{2}{5}\right)$.

The following proposition is immediate from the above discussion.

Proposition 3: Compared to the situation with no labour union (or a competitive labour market), the presence of a domestic labour union makes the consumers better off if $(2-\lambda) c<a<(5-4 \lambda) c$ and $\hat{\alpha}<\alpha<\alpha^{*} \equiv \frac{2(1-\lambda) c}{a-\lambda c}$.

The presence of a labour union may induce firm 1 to charge a less distortionary licensing contract depending on the union's preference for wage over employment, as shown in Proposition 2. Thus, the presence of a labour union creates two opposing effects on the marginal costs of the firms. On one hand, it tends to increase the marginal cost of firm 1 . On the other hand, it tends to reduce the marginal cost of firm 2 by inducing firm 1 to offer a less distortionary technology licensing contract to firm 2 . Hence, the consumers are better off in the presence of a labour union compared to no labour union if the second effect dominates the

${ }_{12} \frac{\partial\left(\lambda w^{d u l}+r^{d u l}-c\right)}{\partial \alpha}=-\frac{9(2+\alpha)(2-5 \alpha)(a-\lambda c)}{(4+5 \alpha(2-\alpha))^{2}}<0$ for $\bar{\alpha}<\alpha<\frac{2}{5}$ 
first effect, which happens if the market size is not large (i.e., $(2-\lambda) c<a<(5-4 \lambda) c)$ and the union's preference for wage over employment is moderate (i.e., $\hat{\alpha}<\alpha<\frac{2(1-\lambda) c}{a-\lambda c}$ ).

Since the unionised wage increases with respect to the market size, $a$, if the market size is large, i.e. $(5-4 \lambda) c<a$, the increase in firm 1's marginal cost due to the presence of a labour union (compared to no labour union) is never less than the reduction in firm 2's marginal cost. Hence, the presence of a labour union will always make the consumers worse off compared to no labour union if $(5-4 \lambda) c<a$.

If $(2-\lambda) c<a<(4-3 \lambda) c, \alpha^{*}>\frac{1}{2}$, implying that Proposition 3 holds for $\alpha=\frac{1}{2}$ and our result holds even if the input supplier is not a labour union but a profit maximising input supplier.

\section{Conclusion}

It is generally believed that if the input supplier charges linear price, market power of the input supplier increases the input price and the final goods price, thus making the consumers worse off compared to the situation with a competitive input market. We show in this paper that this view may not be correct if the final goods producers can adopt strategies to bypass market power of the input supplier.

Considering a monopolist final goods producer, we show that the presence of a labour union induces a monopolist producer to license its technology to a foreign firm, thus increasing product-market competition and reducing the unionised wage. As a result, the presence of a labour union makes the consumers better off compared to the situation with no labour union (or a competitive labour market). 
We further show that, in the case of a duopoly market structure, the presence of a labour union may make the consumers better off compared to a situation with no labour union by inducing the technologically efficient firm to charge a less distortionary technology licensing contract. In this situation, the presence of a labour union makes the consumers better off if the market size is not large and the labour union's preference for wage over employment is moderate.

Our results hold even if the input supplier is not a labour union but it is a profit maximising input producer. Thus, our paper provides important implications about curbing market power of the input suppliers. 


\section{References}

Arya, A. and B. Mittendorf, 2006, 'Enhancing vertical efficiency through horizontal licensing', Journal of Regulatory Economics, 29: 333-342.

Bousquet, A., H. Cremer, M. Ivaldi and M. Wolkowicz, 1998, 'Risk sharing in licensing', International Journal of Industrial Organization, 16: 535-554.

Buckley, P. J. and M. Casson, 1981, 'The optimal timing of a foreign direct investment', Economic Journal, 91: 75-87.

Bughin, J. and S. Vannini, 1995, 'Strategic direct investment under unionized oligopoly', International Journal of Industrial Organization, 13: 127-145.

Economides, N., 1993, 'A monopolist's incentive to invite competitors to enter in telecommunications services', In G. Pogorel (Ed.), Global telecommunications services and technological changes. Elsevier, Amsterdam.

Farrell, J. and N. T. Gallini, 1988, 'Second-sourcing as commitment: monopoly incentives to attract competition', Quarterly Journal of Economics, 103: 673-694.

Faulí-Oller, R. and J. Sandonis, 2002, 'Welfare reducing licensing', Games and Economic Behavior, 41: 192-205.

Feess, E., M. Hoeck and O. Lorz, 2009, 'International technology transfers and competition', Review of International Economics, 17: 1038-1052.

Gallini, N. T. and B. D. Wright, 1990, 'Technology transfer under asymmetric information', Rand Journal of Economics, 21: 147-160.

Hirsch, B. T., 1997, 'Unionization and economic performance: evidence on productivity, profits, investment, and growth'. In: Mihlar, F., (Ed.), Unions and right-to-work laws, Vancouver, B. C., The Fraser Institute, 35-70. 
Horstmann, I. J. and J. R. Markusen, 1987, 'Strategic investments and the development of multinationals', International Economic Review, 28: 109-121.

Horstmann, I. J. and J. R. Markusen, 1992, 'Endogenous market structures in international trade (natura facit saltum)', Journal of International Economics, 32: 109-129.

Inderst, R. and C. Wey, 2003, 'Bargaining, mergers, and technology choice in bilaterally oligopolistic industries', Rand Journal of Economics, 34: 1-19.

Iyer, G. and J.M. Villas-Boas, 2003, ‘A bargaining theory of distribution channels', Journal of Marketing Research, 40: 80-100.

Kabiraj, T. and S. Marjit, 2003, 'Protecting consumers through protection: the role of tariff induced technology transfer', European Economic Review, 47: 113-124.

Katz, M. and C. Shapiro, 1985, 'On the licensing of innovations', Rand Journal of Economics, 16: 504-520.

Macho-Stadler, I., X. Martínez-Giralt and J. D. Pérez-Castrillo, 1996, 'The role of information in licensing contract design', Research Policy, 25: 43-57.

Metcalf, D. and J. Li, 2005, 'Chinese Unions: Nugatory or Transforming? An Alice Analysis', CEP Discussion Paper 708, LSE, Centre for Economic Performance, December.

Milliou, C., E. Petrakis and N. Vettas, 2005, '(In)efficient trading forms in competing vertical chains', Mimeo.

Motta, M., 1992, 'Multinational firms and the tariff-jumping argument: A game theoretic analysis with some unconventional conclusions', European Economic Review, 36: 15571571.

Mottiner, S. and J. P. Johnson, 2000, 'Motivations and risks in international licensing: a review and implications for licensing to transitional and emerging economies', Journal of World Business, 35: 171-188. 
Mukherjee, A., 2007, 'Optimal licensing contract in an open economy', Economics Bulletin, 12: $1-6$

Mukherjee, A., 2008, 'Unionised labour market and strategic production decision of a multinational', Economic Journal, 118: 1621-1639.

Mukherjee, A. and N. Balasubramanian, 2001, 'Technology transfer in horizontally differentiated product-market', Research in Economics, 55: 257-274.

Mukherjee, A., U. Broll and S. Mukherjee, 2008, 'Unionized labor market and licensing by a monopolist', Journal of Economics, 93: 59-79.

Mukherjee, A. and E. Pennings, 2006, 'Tariffs, licensing and market structure', European Economic Review, 50: 1699-1707.

Mukherjee, A. and K. Suetrong, 2012, 'Unionisation structure and outward foreign direct investment', Journal of Institutional and Theoretical Economics, 168: 266-279.

Mukherjee, A. and L.F.S. Wang, 2013, 'Labour union, entry and consumer welfare', Economics Letters, 102: 603-605.

National Science Board, 2008, Science and Engineering Indicators 2008, Arlington, VA: National Science Foundation.

Normann, H.-T., 2009, 'Vertical integration, raising rivals' costs and upstream collusion', European Economic Review, 53: 461-480.

Ordover, J.A., G. Saloner and S.C. Salop, 1990, 'Equilibrium vertical foreclosure', American Economic Review, 80: 127-142.

Poddar, S. and U. B. Sinha, 2010, 'Patent licensing from high-cost to low-cost firm', Economic Record, 86: 384-395.

Rockett, K., 1990, 'The quality of licensed technology', International Journal of Industrial Organization, 8: 559-574. 
Rostoker, M., 1984, ‘A survey of corporate licensing', IDEA, 24: 59-92.

Sen, D. and Y. Tauman, 2007, 'General licensing schemes for a cost-reducing innovation', Games and Economic Behavior, 59: 163-186.

Shepard, A., 1987, 'Licensing to enhance demand for new technologies', Rand Journal of Economics, 18: 360-368.

Shrek, J., 2009, What unions do: how labour unions affect jobs and the economy, Backgrounder (Published by the Heritage Foundation) 2275, 1-10.

Smith, A., 1987, 'Strategic investment, multinational corporations and trade policy', European Economic Review, 31: 89-96.

Tirole, J., 1988, The theory of industrial organization, MIT Press, Cambridge, MA.

Varian, H.R., 1992, Microeconomic analysis, $3^{\text {rd }}$ ed., W.W. Norton \& Company, London, UK.

Vishwasrao, S., 2007, 'Royalties versus fees: how do firms pay for foreign technology?', International Journal of Industrial Organization, 25: 741-759.

Wang, X. H. and B. Z. Yang, 1999, 'On licensing under Bertrand competition', Australian Economic Papers, 38: 106-119.

Wang, X. H., 2002, 'Fee versus royalty licensing in a differentiated Cournot duopoly', Journal of Economics and Business, 54: 253-266.

Yang, L. and K.E. Maskus, 2009, 'Intellectual property rights, technology transfer and exports in developing countries', Journal of Development Economics, 90: 231-236. 